\title{
Institucionalismo Organizacional e Práticas de Governança Corporativa ${ }^{(1)}$
}

\section{Organizational Institutionalism and Corporate Governance}

Luciano Rossoni *

Doutor em Administração pelo CEPPAD/UFPR. Professor do PMDA/UP, Curitiba/PR, Brasil.

Clóvis L. Machado-da-Silva (in memorian)

Ph.D. em Estudos Organizacionais e Estratégia pela Michigan State University, EUA. Professor Titular do CEPPAD/UFPR e Professor do PMDA/UP, Curitiba/PR, Brasil.

* Endereço: Luciano Rossoni

Av. Prof. Pedro Viriato Parigot de Souza, 5300, UP/PMDA, Campo Comprido, Curitiba/ PR, 81280-330.E-mail: Irossoni@gmail.com 


\section{Resumo}

Com este ensaio teórico, buscamos delinear uma visão institucional acerca da governança corporativa, destacando suas dimensões e suas instituições, bem como o processo de institucionalização dessas práticas. Destaque especial é dado ao caráter legitimador da governança, já que a legitimidade constitui ponto central no institucionalismo organizacional. Conforme se destaca na literatura, a legitimidade das práticas de governança fundamenta-se não somente em questões de ordem racional-utilitária, mas também em questões de ordem simbólica e social, como, por exemplo, o ideal de justiça distributiva, em que acionistas minoritários buscam justificar maior controle sobre acionistas controladores e gestores das organizações, pautando-se pela moralidade de tais exigências. Esboçamos alguns elementos do processo de institucionalização das práticas de governança corporativa ao redor do mundo, destacando que a emergência do fenômeno da sua difusão é resultado de uma série de fatores que acabam pressionando os mercados produtivos e de capitais a conformar suas práticas a padrões internacionalmente dominantes. Concluímos este ensaio teórico, dando destaque às implicações de se compreender as práticas de governança, com enfoque no institucionalismo organizacional, desdobrando possibilidades de estudos futuros.

Palavras-chave: governança corporativa; institucionalização; legitimidade; práticas organizacionais; teoria institucional.

\section{ABSTRACT}

In this essay, we outline an institutional approach concerning corporate governance, highlighting its dimensions, institutions, and institutionalization. Special attention is paid to the legitimizing quality of governance, since legitimacy is the central point in organizational institutionalism. The literature claims that the legitimacy of governance practices is based not only on rational-utilitarian questions but also on matters of social and symbolic order, e.g., the ideal of distributive justice, in which minority shareholders seek to justify greater control over controlling shareholders and managers guiding organizations on the morality of such requirements. We delineate some elements of the process of institutionalization of corporate governance practices around the world, noting that the emergence of the phenomenon and its spread is the result of several factors that end up pushing the product and capital markets to conform their practices to internationally prevailing standards. We conclude this theoretical essay by highlighting the implications for understanding the governance practices from the standpoint of organizational institutionalism, unfolding possibilities for future studies.

Key words: corporate governance; institutionalization; legitimacy; organizational practices; institutional theory. 


\section{INTRODUÇÃO}

Desde o advento da grande empresa americana, várias abordagens tentam explicar o fenômeno das grandes corporações, assim como suas relações com o mercado de capitais. Entre essas abordagens, a que tem papel mais destacado, em volume de estudos, de orientações para o mercado e de pesquisa é a econômico-financeira. Isso ocorre porque, como apontam Fligstein e Freeland (1995), grandes corporações são controladas por executivos da área de finanças e é sob a visão desses atores que as estratégias corporativas são definidas.

Em face do exposto, todos os elementos relacionados à gestão e ao controle dessas organizações tendem a ser vistos como problemas de ordem econômica ou legal, principalmente entre aquelas organizações de capital aberto, que necessitam do mercado de ações para financiar suas atividades. Essa perspectiva econômico-financeira serviu muito bem durante décadas, dando conta de boa parte dos elementos relacionados ao controle e estratégia das grandes corporações. Porém escândalos recentes envolvendo grandes corporações americanas, bem como empresas de auditoria que, até naquele momento, eram consideradas sólidas e respeitáveis, afetaram a credibilidade tanto das organizações envolvidas, quanto do mercado como um todo. Isso apontou para mudanças necessárias na forma de entender e gerir essas organizações, ou seja, mudança na governança corporativa. Percebeu-se, portanto, que o controle das organizações é um tema demasiado importante e complexo para ser tratado somente no campo de finanças e por executivos financeiros, tal como sob uma ótica econômico-legal.

Assim, diante da crise de legitimidade que tais escândalos geraram no mercado, que não foram possíveis de ser resolvidos seguindo apenas uma lógica utilitarista de atuação, teóricos e práticos das organizações estão buscando compreender o fenômeno da governança corporativa sob diferentes lógicas, entre elas a institucional.

Dessa forma, objetivamos com este ensaio teórico ${ }^{(2)}$ delinear uma visão institucional acerca da governança corporativa, destacando suas dimensões e suas instituições tal como o processo de institucionalização de tais práticas. Destaque especial é dado ao caráter legitimador da governança, já que a legitimidade, enquanto conceito, é ponto central no institucionalismo organizacional (Scott, 2008). Para tanto, dividimos esse ensaio em duas seções principais, em 
que na primeira discorremos sobre as práticas de governança corporativa, suas dimensões e suas instituições e, na segunda, ilustramos a institucionalização de tais práticas ao redor do mundo e no Brasil.

\section{Práticas de Governança Corporativa}

Um dos principais interesses do institucionalismo organizacional é entender a difusão de práticas organizacionais, assim como sua incorporação em diferentes campos organizacionais (Greenwood, Suddaby, \& Hinings, 2002). Entre uma diversidade de práticas que se vêm difundindo ao redor do mundo (vide, por exemplo, difusão de programas de gestão da qualidade em Abrahamson \& Fairchild, 1999), uma vem ganhando especial projeção em função de sua emergência, enquanto possível solução para recorrentes escândalos e crises corporativas (Organization for Economic Co-Operation and Devolopment [OECD], 2004): a difusão de práticas de governança corporativa (Aguilera \& Cuervo-Cazurra, 2004; Aguilera \& Jackson, 2003; Capron \& Guillén, 2009; Enrione, Mazza, \& Zerboni, 2006; Zattoni \& Cuomo, 2008).

Na perspectiva institucional, práticas organizacionais são "ações sociais regularizadas e recorrentes que continuamente constroem e reconstroem a organização como um sistema social espaciotemporalmente delimitado" (Albuquerque \& Machado-da-Silva, 2009, p. 632). Especificamente, por práticas de governança corporativa, entre uma diversidade de definições (vide exemplos na Tabela 1), seguimos Davis (2005), que opta pela definição de Blair (1995, p. $3)$, que a observa como

todo o conjunto de meios jurídicos, culturais e arranjos institucionais que determina o que as empresas de capital aberto podem fazer, quem pode controlálas, como seu controle é exercido, e como os riscos e retornos das atividades das quais são responsáveis são alocadas.

Adicionalmente, entendemos que tais práticas, enquanto institucionalizadas, apresentam conteúdo normativo, que, por sua vez, podem ter papel legitimador. 
Tabela 1

\section{Exemplos de Definições de Governança Corporativa}

\begin{tabular}{ll}
\hline Estudo & Definição \\
\hline Blair (1995) & $\begin{array}{l}\text { Todo o conjunto de meios jurídicos, culturais e arranjos institucionais que determina o que as } \\
\text { empresas de capital aberto podem fazer, quem pode controlá-las, como seu controle é } \\
\text { exercido, e como os riscos e retornos das atividades das quais são responsáveis são alocados. }\end{array}$ \\
Conjunto de práticas que tem por finalidade aperfeiçoar o desempenho de uma companhia ao \\
proteger todas as partes interessadas, tais como investidores, empregados e credores, \\
facilitando o acesso ao capital.
\end{tabular}

Nota. Legenda: Comissão de Valores Mobiliários [CVM]; Instituto Brasileiro de Governança Corporativa [IBGC]; Organization for Economic Co-operation and Development [OECD]. Fonte: elaborado pelos autores.

Diferentemente da maior parcela de práticas organizacionais, as práticas relacionadas à governança corporativa envolvem a esfera institucional da organização, já que seu conjunto de decisões envolve aspectos estratégicos e institucionais, focando primordialmente as necessidades ambientais, tanto como as relações com shareholders (acionistas da corporação, também conhecidos como stockholders) e stakeholders (Davis, 2005). Sendo assim, o locus da governança corporativa é o topo da firma e seu sistema de decisões estratégicas (Bertucci, Bernardes, \& Brandão, 2006; Roe, 2005), assim como todas as formas de controle e coordenação que a alta gerência emprega em sua esfera de atuação (Fiss, 2008).

Como prática organizacional, um aspecto fundamental da governança corporativa é a divisão de autoridade entre o conselho de administração (board) e presidência executiva (Chief Executive Office [CEO]), por um lado, e dos acionistas (stockholders), por outro (ROE, 2005), o que remete à separação entre propriedade e controle (Berle \& Means, 1932/1991), tal como na divisão do trabalho entre diferentes níveis de gestão da corporação (Fligstein \& Freeland, 1995). No entanto, como diferentes partes atuam com papéis distintos no processo decisório das grandes organizações, principalmente aquelas de capital aberto, um problema básico de interdependência desses papéis gera o que os economistas chamam de problema da agência (Jensen \& Meckling, 1976), que, por consequência, também aumenta os custos de transação (Williamson, 1996). 
Na concepção econômico-contratual das organizações (Jensen \& Meckling, 1976; Williamson, 1996), uma firma, ao invés de ser definida por sua função de produção, visão clássica, é tida como entidade, cuja vocação é coordenar um emaranhado de contratos, objetivando redução de custos de transação, entre eles os custos de agência. Nesta perspectiva, uma relação de agência é definida como "um contrato entre uma ou mais pessoas (o principal), engajando outra pessoa (o agente), para exercer algum serviço em seu lugar, envolvendo a delegação de alguma autoridade para a tomada de decisão por parte desse agente" (Jensen \& Meckling, 1976, p. 308). Dessa separação entre propriedade (acionistas da organização) e agência (executivos) surge o problema da relação entre principal e agente, pois ela sempre vai gerar algum tipo de custo para o primeiro. Para Jensen e Meckling (1976), os custos da agência são formados por: (1) gastos oriundos da necessidade de se monitorar o agente; (2) o custo de intermediação do agente; (3) a perda residual. Por perda residual, esses autores entendem como a redução experimentada pelo principal por causa da divergência entre agente e principal.

Diante da presença de tais custos, principalmente aqueles originados da atitude oportunista de alguns agentes (Shleifer \& Vishny, 1997; Zattoni \& Cuomo, 2008), para reduzi-los, companhias, assim como diferentes agentes do mercado, buscam proteger seus investimentos, tal como garantir seus direitos por meio de práticas de governança corporativa (Shleifer \& Vishny, 1997), partindo da premissa que exista uma solução eficiente para tal problema. Todavia, entendendo que mercados, assim como organizações, nunca apresentam uma disposição totalmente eficiente, já que, como estruturas sociais, estão imersos em arranjos institucionais e legais mais amplos, o resultado de tais práticas de governança são altamente contingentes (Aguilera \& Jackson, 2003; Fiss, 2008). Por isso para se compreender como as práticas de governança corporativa são incorporadas em mercados distintos, é necessário compreender cada uma de suas dimensões, assim como destacar o papel de cada uma das instituições envolvidas no processo.

\section{Dimensões da Governança Corporativa e Legitimidade}

Enquanto sistema que governa as relações da corporação, principalmente em volta de seus três principais atores (acionistas, executivos e conselho de administração), práticas de governança envolvem duas concepções de relacionamentos entre esses atores, configurando-se em duas dimensões: uma vertical, outra horizontal (Roe, 2005). Como aponta Roe (2005), a dimensão vertical ocorre entre executivos e acionistas minoritários, cuja propriedade é dispersa, não havendo nenhum acionista dominante (modelo americano e britânico de propriedade). Assim, o foco da governança é garantir que executivos e conselho de administração atuem de acordo com os interesses dos acionistas, além de, é claro, serem suficientemente competentes para gerir a organização (Berle \& 
Means, 1932/1991). Como isso não ocorre por vontade própria dos agentes (executivos e conselheiros), há uma série de artefatos e mecanismos institucionalizados que regem as relações entre eles e o principal, neste caso os acionistas minoritários (vide Blair, 1995; Davis, 2005; Fiss, 2008; Fligstein \& Freeland, 1995; Roe, 2005; Shleifer \& Vishny, 1997). Já a dimensão horizontal das relações de governança ocorre quando há um acionista dominante que potencia $o$ atendimento de seus interesses em detrimento dos anseios dos acionistas minoritários (modelo europeu, asiático e latino-americano). Nessas circunstâncias, o principal objetivo de mecanismos e instituições relacionados a práticas de governança é interromper ações autointeressadas do controlador.

A diferenciação das relações entre acionistas, conselheiros e executivos nas duas dimensões apontadas acima ocorre porque diferentes fatores culturais, políticos, jurídicos e institucionais de maior amplitude condicionam a adoção de práticas de governança nas companhias de capital aberto (Aguilera \& Jackson, 2003; Fligstein \& Choo, 2005; Fligstein \& Freeland, 1995). Em face desse condicionamento, em ambientes institucionais em que a proteção aos direitos dos acionistas é pequena, existe uma tendência de a estrutura de propriedade ser mais concentrada (La Porta, Lopez-de-Silanes, Shleifer, \& Vishny, 1998), o que leva a que os sistemas de governança apresentem uma forma horizontal, enquanto em ambientes em que a proteção aos acionistas é maior, há uma tendência de pulverização das ações, diluindo a propriedade.

Pelo indicado acima, fatores institucionais e sociais mais amplos condicionam sistemas e práticas de governança. Portanto outra dimensão é apontada no institucionalismo organizacional e na sociologia econômica: práticas de governança, além de resolverem problemas entre agente e principal, elas fundamentalmente devem ser tidas como legítimas na sociedade (Aguilera \& Cuervo-Cazurra, 2004; Roe, 2005). Isso porque, como ressaltam Jones e Goldberg (1982), existe uma expectativa de que as corporações atuem de maneira socialmente responsável ou tida como legítima. Assim, uma visão estritamente econômica acerca das práticas de governança tende a ser questionável, mesmo que boa parte do discurso sobre governança corporativa se confunda com o de financeirização das organizações, havendo prevalência da lógica instrumental financeira sobre as demais (Grün, 2003).

Em face do exposto, a definição de práticas e códigos de governança não tem papel somente relacionado à eficiência dos mercados, mas também tem papel legitimador (Aguilera \& Cuervo-Cazurra, 2004; Roe, 2005). Por trás desse papel está um ideal de justiça distributiva, em que acionistas minoritários, assim como outros stakeholders desfavorecidos pelas instituições vigentes, buscam justificar maior controle sobre acionistas controladores e gestores das organizações, respaldados na moralidade de tais ações, mesmo que somente restritas à esfera econômica (vide, também, Grün, 2003). 
Williams e Findlay (1984) vão mais além da análise da legitimação enquanto ideal de justiça distributiva, relacionando-a com o desenvolvimento histórico e social da sociedade ocidental, mais especificamente a anglo-saxônica. Eles fazem interessante analogia sobre as grandes corporações americanas: a constituição legal de uma corporação torna-se uma república em miniatura, os acionistas são os eleitores, os conselheiros são o poder legislativo, promulgando políticas gerais, buscando comprometer os executivos com sua realização. O judiciário é desnecessário. Nessa concepção, acionistas têm funções diferentes, em que os primeiros não interferem diretamente nas decisões dos segundos, a não ser, é claro, por meio de revisões constitucionais. Assim, como os acionistas não podem atuar diretamente na organização, muitas vezes sem direito de voto, o que lhes resta é buscar mecanismos pautados por princípios socialmente legítimos para garantir seus interesses.

Em um primeiro momento, esses interesses restringem-se a uma lógica econômica das organizações, como pode ser visto, ao se analisarem os códigos de boas práticas de governança corporativa, que, em poucas palavras, apontam a maximização do valor da organização, que, por sua vez, se desdobra em aumento da riqueza dos acionistas (Pound, 1995). Porém, se observarmos os princípios que regem tais práticas de governança, que, como qualquer prática, apresentam um conteúdo normativo, nitidamente há uma tentativa de expandir os interesses dos entes mais fracos das relações corporativas para um senso de igualdade entre acionistas minoritários e controladores, por um lado, e entre acionistas e gestor, por outro. Por exemplo, códigos de boas práticas de governança internacionalmente disseminados, como o da OECD (2004), apontam pelo menos três princípios básicos que se relacionam com a ideia de justiça distributiva: transparência (disclosure), equidade (fairness) e responsabilidade (accountability), cujos preceitos foram seguidos por códigos de boas práticas de governança também no Brasil (vide IBGC, 2006, 2009).

A aceitação dos princípios de governança pelas organizações indica conformidade a padrões de conduta legitimamente aceitos (Enrione et al., 2006). Entendendo esses três princípios como mecanismos, nas palavras de Grün (2003, p. 140),

a boa governança corporativa seria o instrumento que propiciaria a deflagração de um ciclo virtuoso. Transparência nos procedimentos contábeis e administrativos da empresa de capital aberto e respeito aos direitos dos acionistas minoritários são as bases de sustentação da nova institucionalidade.

Na mesma linha de raciocínio, Stanfield e Carrol (2004, p. 363) apontam que "o poder [das organizações] é exercido legitimamente quando ele é empregado dentro dos limites das regras e normas dominantes, isto é, quando ele é empregado de forma transparente". Contudo, tais regras e normas dominantes não são ditadas simplesmente por aspectos relacionados à eficiência da gestão das corporações, nem a quanto eficientes são as regras de governança corporativa. Como foi apontado anteriormente, 
elas envolvem aspectos culturais, políticos e institucionais de cada sistema social (North, 1990), que condicionam a configuração das práticas de governança, assim como sua legitimidade (Aguilera \& Cuervo-Cazurra, 2004), mesmo perante uma tentativa de homogeneização de tais práticas ao redor do mundo.

Na concepção de Fligstein e Freeland (1995), as práticas de governança mundialmente disseminadas, quando incorporadas nos mercados nacionais, apresentam uma nova configuração, que é função de três fatores: grau de industrialização da economia; papel do estado em regular os direitos de propriedade e as regras de cooperação e competição entre firmas; e o papel das elites nacionais. Mais tarde, Fligstein e Choo (2005) expandiram tal concepção em um esquema analítico (vide Figura 1) para se compreender como tais fatores afetam as estruturas de governança, que, por sua vez, impactam nos resultados econômicos de países e organizações.

\section{Societal conditions Govenance structures}

(formal law)

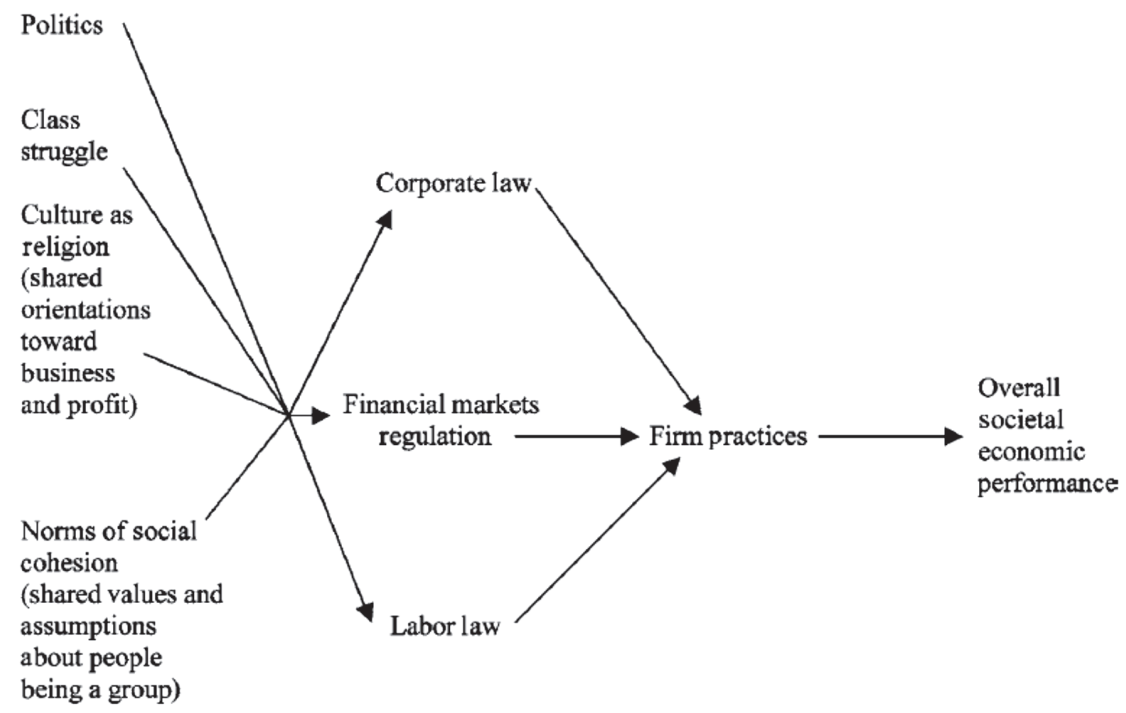

Figura 1. Modelo Institucional de Relação entre Fatores Sociais, Leis e Governança Corporativa.

Fonte: Fligstein, N., \& Choo, J. (2005). Law and corporate governance (p. 68). Annual Review of Law and Social Science, 1, 61-84.

De acordo com o modelo institucional proposto por Fligstein e Choo (2005), as condições sociais (políticas, luta de classes, cultura religiosa e normas de coesão social) condicionam os elementos estruturais de governança (leis corporativas, regulamentação dos mercados, leis trabalhistas), que, por sua vez, afetam a adoção de práticas organizacionais (práticas de governança), tais como têm efeito sobre a 
eficiência das firmas. Para esses autores, as condições políticas não envolvem somente o tipo de sistema político (democracia ou ditadura), mas se relacionam também com a tradição legal e jurídica do país. Por exemplo, a literatura aponta que se o tipo de sistema jurídico, se consuetudinário (common law) ou positivo (civil law), afeta a proteção aos direitos dos acionistas minoritários (La Porta et al., 1998). Já as lutas de classes são relevantes, porque elas consideram como o conflito entre proprietários e trabalhadores afeta as relações de propriedade, o desenvolvimento dos mercados financeiros e as leis trabalhistas. Por sua vez, a cultura religiosa tem papel importante na estruturação da governança, porque afeta diretamente os limites da aquisição e geração de riqueza pelas corporações. Por fim, outro aspecto fundamental é o conjunto de crenças e pressupostos acerca das relações entre indivíduos em grupos sociais, o que diretamente está relacionado com o grau de confiança nas relações e com a imersão social das corporações (Granovetter, 1985).

O modelo institucional de Fligstein e Choo (2005) é muito similar a outros modelos do institucionalismo organizacional (Scott, 1994, 2008) e do novo institucionalismo na sociologia econômica (Nee \& Swedberg, 2005) (vide Figura 2). A principal diferença está na ênfase dada às estruturas sociais intermediárias, os campos organizacionais, que se configuram como a arena onde as formas e práticas organizacionais são disseminadas, que, em nosso caso, é o sistema no qual as práticas de governança realmente atuam.

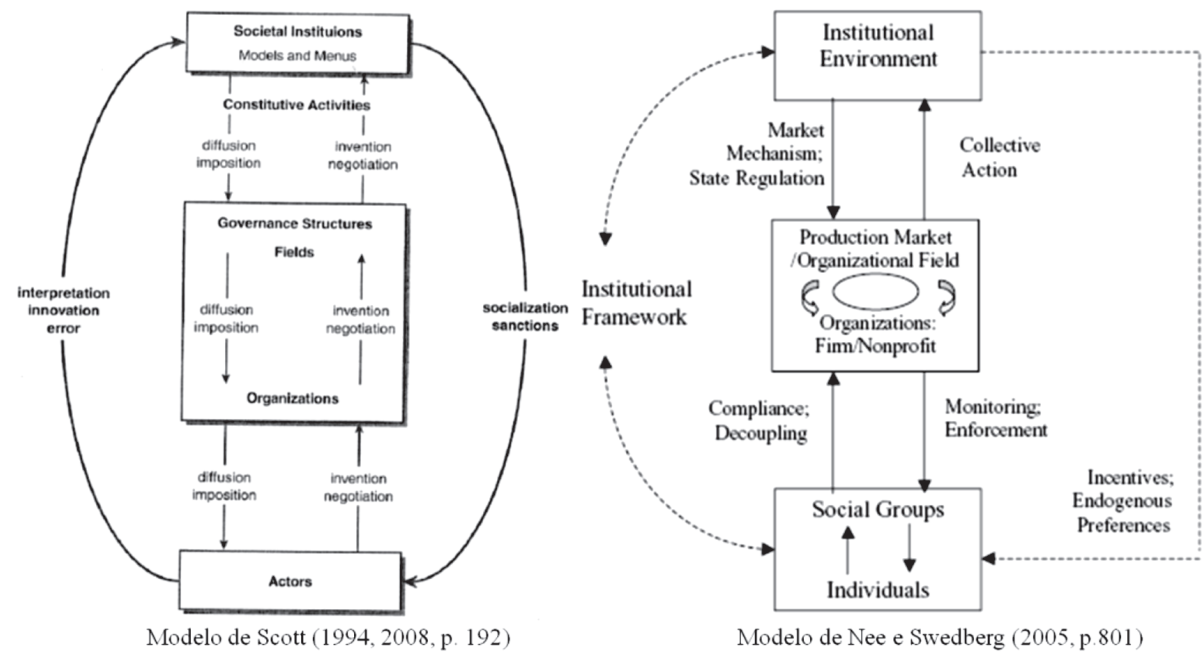

Figura 2. Modelos Institucionais da Teoria das Organizações e da Sociologia Econômica.

Fonte: Scott, W. R. (2008). Institutions and organizations: ideas and interests (3th ed., p. 192). Thousand Oaks: Sage; Nee, V., \& Swedberg, R. (2005). Economic sociology and new institutional economics (p. 801). In C. Ménard \& M. M. Shirley (Eds.), Handbook of new institutional economics (pp. 789-818). Netherlands: Springer. 
Tais modelos consideram o condicionamento de instituições sociais mais amplas, mas também aceitam o caráter socialmente construído das relações estruturais nos sistemas sociais. Assim, considerando as relações corporativas como uma das dimensões relacionais do campo organizacional das grandes corporações, algumas instituições peculiares a esse campo se destacam, assegurando a reprodução de práticas de governança corporativa. Como ressalta Roe (2005), tais instituições definem quais são as obrigações sociais das organizações, além de atuarem como condutores (carriers, segundo Scott, 2008) das formas como os atores organizacionais respondem a tais obrigações, assim como regem a posição desses atores no campo.

\section{Instituições da Governança Corporativa}

De acordo com Roe (2005), a governança corporativa, enquanto prática social, apresenta um conjunto de instituições. Por instituições da governança corporativa entendemos como uma espécie de sistema de disposições financeiras sobre as corporações, de amplitude global, cujos dispositivos se combinam para orientar os executivos e as organizações sobre como gerar valor para os acionistas (Davis, 2005). Tais instituições são apontadas a seguir.

Mercados. Segundo Roe (2005), o mercado é a mais importante instituição da governança corporativa. Sob uma lógica institucional, ele pode ser entendido como campo organizacional (Nee \& Swedberg, 2005; Scott, 2008), já que é a esfera reconhecida pelas organizações como referência de ação. Para esse autor, há três mercados centrais: o mercado produtivo, o mercado de capitais, e o mercado de trabalho executivo, todos eles importantes porque fornecem os recursos necessários para a sobrevivência, crescimento e gestão das organizações. Os três tipos condicionam as práticas de governança; contudo, como os mercados sempre são imperfeitos, além de que não apresentam informação suficiente sobre a operação das organizações, outras instituições relacionadas à governança corporativa podem suprir sua ineficácia de controle.

Conselho de administração. Em sistemas verticais de governança corporativa (com acionistas pulverizados), o conselho de administração é fundamental, pois é ele que defende o interesse dos acionistas (principal) na organização, cobrando dos executivos (agente) que eles atuem de acordo com os interesses dos shareholders. Já em relações horizontais de governança, em que o acionista majoritário controla o conselho de administração, a influência e autoridade do conselho diminuem, tendendo a gerar maiores custos de agência para acionistas minoritários (Shleifer \& 
Vishny, 1997). Em ambos os tipos, mas por diferentes razões, grande parte do conteúdo normativo das boas práticas de governança existe em função de garantir que o conselho atue de forma efetiva, não somente de forma figurativa. No caso de sistemas verticais, o foco incide sobre a necessidade de os executivos atuarem de acordo com os interesses dos acionistas e não motivados por necessidade própria; em sistemas horizontais, o principal papel do conselho é defender os acionistas minoritários do oportunismo do controlador, normalmente por meio de conselheiros externos, não diretamente ligados à gestão da organização.

Transparência na informação e gate-keepers. Acionistas, assim como o mercado, precisam de informação segura sobre a organização para poder precificar os papéis da companhia. Tal instituição está relacionada principalmente com os mecanismos formais de prestação de contas das organizações, entre eles as normas contábeis, nas quais existe a expectativa de que essas informações sejam confiáveis, e que sejam divulgadas de forma que elas não privilegiem nenhum membro da organização. Além disso, esperase que organizações de capital aberto disponibilizem voluntariamente qualquer tipo de informação relevante para o mercado (princípio da disclosure), já que as informações são fundamentais para que eles funcionem de forma eficiente (Fama, 1970). Tais informações apresentam alguns gate-keepers (guardiões da norma), membros externos das organizações, responsáveis pela fidedignidade das informações, como, por exemplo, advogados, contadores e analistas de risco.

Coalizões de acionistas. Em situações onde a propriedade da organização está dispersa, uma alternativa para que os acionistas tenham maior controle sobre as ações dos executivos, evitando-se principalmente comportamentos oportunistas, é por meio da coalizão (Roe, 2005). Uma das formas de coalizão existente é denominada takeover (tomada de controle da organização). Operações de tomada de capital (takeover) ocorrem quando uma organização (companhias, investidores institucionais, governos, fundos de pensão, entre outros) adquire o controle de uma organização por meio da troca ou compra de ações da companhia alvo da tomada de capital, podendo ocorrer de forma amigável, ou, em alguns casos, de forma hostil. A aquisição do controle corporativo por meio do takeover pode acarretar problemas de legitimidade, principalmente entre aquelas aquisições que ocorrem de forma hostil. Por isso boa parte das nações apresenta algum tipo de lei ou regulamento que limitam a possibilidade de takeover (La Porta et al. 1998; Roe, 2005; vide Gorga, 2004, para análise da regulamentação sobre takeover no Brasil). Outra forma de coalizão ocorre por meio de investidores institucionais. Esses investidores possuem grande 
influência no mercado por reunirem grandes somas de capital de terceiros, adquirindo o direito de representá-los perante os conselhos das organizações nas quais investem. A busca de um lugar no assento do conselho das companhias é também uma estratégia utilizada por investidores individuais, por meio do blockholding (aquisição de grande parcela de ações que garantem o direito a assento no conselho). Dessa forma, com sua posição garantida, blockholders podem efetivamente fazer com que os executivos atuem de acordo com os seus interesses.

Sistema de compensação de executivos e conselheiros. Além do controle direto feito por meio de representantes de acionistas no conselho de administração, outra prática institucionalizada de governança corporativa, que objetiva alinhar executivos, conselheiros e interesses dos proprietários, é o sistema de remuneração de executivos e conselheiros. Segundo Roe (2005), o funcionamento de mecanismos de remuneração é simples: como boa parcela de remuneração dos executivos é feita por meio de opções de ações da organização em que trabalham, se elas se valorizam, executivos ganham mais dinheiro. Tal mecanismo de incentivo é simples, pois considera como interesse do acionista a valorização da companhia e das ações. Mesmo havendo fortes indícios de que tais incentivos apresentam limitações (Roe, 2005), há fortes indícios de que executivos que aumentam o valor da companhia são mais bem remunerados que os de companhias com fraca valorização (Chowdhury \& Wang, 2009).

Profissionalismo e normas de conduta. Os mecanismos de compensação consideram somente o aspecto utilitarista da relação dos executivos e conselheiros com as companhias. Valores, crenças, e qualquer tipo de atributo social e psicológico são deixados de lado. Todavia o comportamento dos executivos considera também o senso de se fazer um trabalho bem feito. Além de dinheiro, eles buscam reconhecimento pelo trabalho, assim como necessitam de aprovação social. Para Roe (2005), essas normas envolvem a dimensão profissional da governança corporativa, que, mesmo condicionando em grande escala as práticas organizacionais por meio do isomorfismo normativo (vide Scott, 2008), pouco se buscou entender como elas afetam as organizações.

Legislação corporativa. Instituições legais não só determinam as regras do mercado financeiro e corporativo, como também condicionam como se configuram as práticas de governança corporativa e a estrutura de propriedade (Fligstein \& Choo, 2005; Fligstein \& Freeland, 1995; La Porta et al., 1998). Regras jurídicas têm o poder de coibir ações fraudulentas e irresponsáveis dos executivos e conselheiros, pois esses podem ser processados por seus atos: o fruto de tal processo pode ser pesada multa, como desapropriação de seus 
bens (Roe, 2005). Instituições legais também podem explicar a diferenciação das práticas de governança internacionalmente (Fligstein \& Choo, 2005; Zattoni \& Cuomo, 2008). Por exemplo, La Porta et al. (1998) demonstram que, em países onde existe pouca proteção dos investidores, assim como dos acionistas minoritários, tende a haver uma estrutura de capital mais concentrada (sistema horizontal). Contudo mesmo considerando aspectos culturais nacionais, na visão de La Porta et al. (1998), tais aspectos são tidos como epifenômenos, já que em suas análises, assim como de alguns institucionalistas econômicos (p.ex. North, 1990; Williamson, 1996), desconsidera-se o caráter socialmente construído das normas jurídicas, tais como as estruturas de dominação vigentes em cada sociedade e seus grupos de interesse (Grün, 2003). Outro aspecto relevante que cumpre considerar nas instituições legais é a consequência de sua ausência: sem meios jurídicos suficientemente válidos para garantir os direitos dos investidores, é provável que as instituições do mercado busquem criar mercados diferenciados (p.ex. Novo Mercado da Bolsa de Valores de São Paulo [BOVESPA] no Brasil e Neuer Markt da bolsa alemã), com câmaras de arbitragem e regras próprias, regidas por contratos assinados entre gestores do mercado com as organizações interessadas em dispor suas ações em tais mercados.

Estrutura de capital. Outra instituição da governança, segundo Roe (2005), é a estrutura de capital, referindo-se à relação entre a quantidade de obrigações da companhia (empréstimos, debêntures, entre outros) e suas ações. De acordo com Roe (2005), as práticas e estratégias de financiamento das organizações estão diretamente relacionadas com as atitudes de executivos. Por exemplo, em organizações nas quais existe folga de recursos, com pouco endividamento, a pressão exercida sobre os executivos é baixa. Em situações inversas, com alto grau de endividamento (situação comum no mercado americano), o efeito se inverte: executivos são extremamente pressionados para obter melhores resultados.

Sistema de gestão de falências. A última instituição que Roe (2005) destaca é o sistema de gestão de falências. Apesar de não ser uma das mais importantes, ela é fundamental, pois regulamenta como algumas economias tratam o problema da recuperação das organizações. Em casos de insolvência, ou seja, quando a dívida das organizações se torna impagável em determinado horizonte de tempo, a maioria das normas jurídicas vigentes nas nações contemporâneas concedem aos credores o direito de liquidarem a empresa, em situações mais graves, ou mudar seu controle, quando esse ainda é factível.

Todas as instituições apontadas acima, que não cerram a quantidade de instituições da governança corporativa, apresentam algum grau de 
interdependência, assim como variabilidade de importância de um ambiente institucional para outro. Como enfatizamos, a forma como tais práticas foram socializadas também condiciona o alinhamento entre elas, assim como seu grau de legitimação (Enrione et al., 2006). Contudo as instituições destacadas por Roe (2005) dão conta de um modelo predominantemente anglo-saxônico. Dessa forma, já que cada nação apresenta uma lógica distinta de governança (Aguilera \& Jackson, 2003), por que então elas estão sendo amplamente disseminadas ao redor do mundo? É o que buscaremos entender no próximo tópico.

\section{Institucionalização das Práticas de Governança Corporativa}

Como apontamos anteriormente, existem várias evidências de que cada país apresenta um contexto institucional específico (Fligstein \& Choo, 2005; Fligstein \& Freeland, 1995; La Porta et al., 1998) que, por sua vez, condiciona a organização da economia de forma também peculiar (Aguilera \& Jackson, 2003). Todavia, apesar de todas as diferenças apontadas e destacadas entre esses sistemas econômicos e sociais, práticas organizacionais são disseminadas entre países e organizações que pouco se assemelham àqueles nos quais tais práticas foram concebidas (Abrahamson \& Fairchild, 1999). Assim, usa-se o mesmo remédio para problemas de natureza diferente, sem ao menos saber se existe algum sintoma ou se a causa do problema é a mesma.

Apesar de, em alguns casos, essa atitude aparentar não ser racional, se compreendermos que organizações em diferentes nações compartilham entre si recursos, mercados e produtos, espera-se que elas tenham algum grau de interação. Assim, se elas mantêm laços entre si, delineia-se, mesmo que de forma embrionária, a concepção de um sistema de organizações que vai além das fronteiras nacionais. Desse grau de sistematização das relações organizacionais ao redor do mundo, mecanismos institucionais, como isomorfismo e estruturação, fomentam a disseminação de formas e práticas organizacionais por razões que vão além da eficiência de tais práticas (Zattoni \& Cuomo, 2008). Portanto, incorporando-se esses elementos institucionais no entendimento do ambiente organizacional, pressupõe-se que mudanças em formas organizacionais são dirigidas considerando tanto a eficiência de tais formas quanto a legitimidade (Fligstein \& Freeland, 1995; Meyer \& Rowan, 1977).

Não seria diferente com as práticas de governança corporativa. Sua difusão e institucionalização envolvem tanto aspectos relacionados à eficiência da prática 
em si quanto em relação ao aspecto da legitimidade que elas geram (Aguilera \& Cuervo-Cazurra, 2004; Enrione et al., 2006; Meyer \& Rowan, 1977; Tolbert \& Zucker, 1983; Zattoni \& Cuomo, 2008). Em face do exposto, para compreender como essas práticas se disseminam ao redor do mundo, definimos difusão de práticas como inovação dentro de um sistema social (entre eles o mercado de ações e corporativo), apesar de que tal inovação não necessariamente implique melhoria, mas uma mudança no estado corrente das coisas (Strang \& Macy, 2001). Já por institucionalização entendemos como “o processo por meio do qual os componentes da estrutura formal se tornam amplamente aceitos, necessários e apropriados, servindo para legitimar as organizações" (Tolbert \& Zucker, 1983, p. 25 , tradução nossa).

Sob essas definições, podemos compreender o processo de difusão e de disseminação de práticas de governança corporativa ao redor do mundo por meio de mecanismos relacionados tanto à eficiência de tais práticas, quanto referentes à legitimação que a aceitação ao seu conteúdo normativo proporciona (Aguilera \& Cuervo-Cazurra, 2004; Fiss, 2008). Define-se, assim, que a adoção de códigos e práticas de governança são inovações feitas por mercados nacionais, sinalizando seu compromisso com a consolidação de um sistema de governança corporativa. Ressalta-se, é claro, que a adoção de tais práticas está imersa em sistemas sociais mais amplos, cujas estruturas de legitimação, dominação e significação condicionam sua teorização (Greenwood et al., 2002).

A emergência do fenômeno da difusão de práticas de governança é resultado de uma série de fatores que acabam pressionando os mercados produtivos e de capitais a conformar suas práticas de governança a padrões internacionalmente dominantes. Na concepção de Aguilera e Cuervo-Cazurra (2004), dois processos têm aumentado a necessidade percebida de mecanismos de monitoramento e de esquemas de incentivos para promover sistemas de governança corporativa. Em primeiro lugar, o processo de globalização, que envolve a liberalização e a internacionalização das economias, a integração de mercados financeiros (Zattoni \& Cuomo, 2008), o desenvolvimento das tecnologias de comunicação e informação. Em segundo lugar, a transformação da estrutura de propriedade das organizações por meio do crescimento de investidores institucionais, da desestatização de economias e do aumento do ativismo dos acionistas.

Em face desses antecedentes, aqueles países que buscaram adotar um sistema de governança mais efetivo, implementando direitos aos acionistas, aumentando o papel dos conselheiros e desenvolvendo formas de os mercados serem mais transparentes e eficientes (vide Monks \& Minow, 2004), tornaram-se mais atrativos para os investidores locais e estrangeiros (La Porta et al., 1998). 
Apesar dos benefícios de tais práticas para as organizações e para os países, a mudança em sistemas de governança é árdua, porque tais práticas estão imersas no ambiente institucional nacional (Fiss, 2008; Nee \& Sweedberg, 2005; North, 1990). Entre algumas das dificuldades de se modificarem práticas de governança está a necessidade de mudanças na legislação, que, por sua vez, dependem de acordos entre políticos e elite corporativa (Zattoni \& Cuomo, 2008). Como tais mudanças geram redistribuição de poder e autoridade, elas também afetam interesses de algumas elites locais, levando-as a resistir à adoção de tais práticas (Roe, 2005).

O caminho legislativo para alterar as práticas de governança tende a ser difícil; por isso alguns mercados buscam uma alternativa para alavancar seu sistema de governança corporativa: a criação de códigos de boas práticas de governança. Como foi indicado anteriormente, boas práticas de governança são "um conjunto de melhores práticas sobre o comportamento e a estrutura do conselho de administração de uma empresa" (Aguilera \& Cuervo-Cazurra, 2004, p. 417). Tais práticas têm sido designadas como forma de minimizar deficiências no sistema de governança dos países, por meio dos seguintes mecanismos: mudanças na composição do conselho; aperfeiçoamento do relacionamento entre acionistas e executivos; aumento na transparência e confiabilidade da informação; criação de mecanismos mais efetivos de seleção e remuneração de diretores; entre outros (vide sugestões de boas práticas de governança corporativa em IBGC, 2006, 2009; OECD, 2004).

Mas, na verdade, o que precipitou o avanço dos códigos de governança corporativa ao redor do mundo foi uma série de escândalos que ocorreram no início deste século, que envolviam grandes corporações, como, por exemplo, Enron, WorldCom e Global Crossing nos Estados Unidos, Parmalat e Círio na Itália, Ahold na Holanda. Por consequência, a publicação do Ato Sarbanes-Oxley em 2002, que impôs medidas mais rígidas às organizações americanas sobre atitudes contábeis fraudulentas também fomentou a disseminação de tais códigos (Borgerth, 2007; IBGC, 2006).

Como pode ser observado na Figura 3, após a ocorrência de tais escândalos de companhias tidas como corporativamente responsáveis, como, por exemplo, a Enron (final do ano de 2001), assim como uma das cinco grandes empresas de auditoria, a Arthur Andersen (ano de 2002), o número de códigos de boa governança publicados ao redor do mundo apresentou um aumento representativo, refletindo a preocupação do mercado em achar respostas para a crise de legitimidade. 


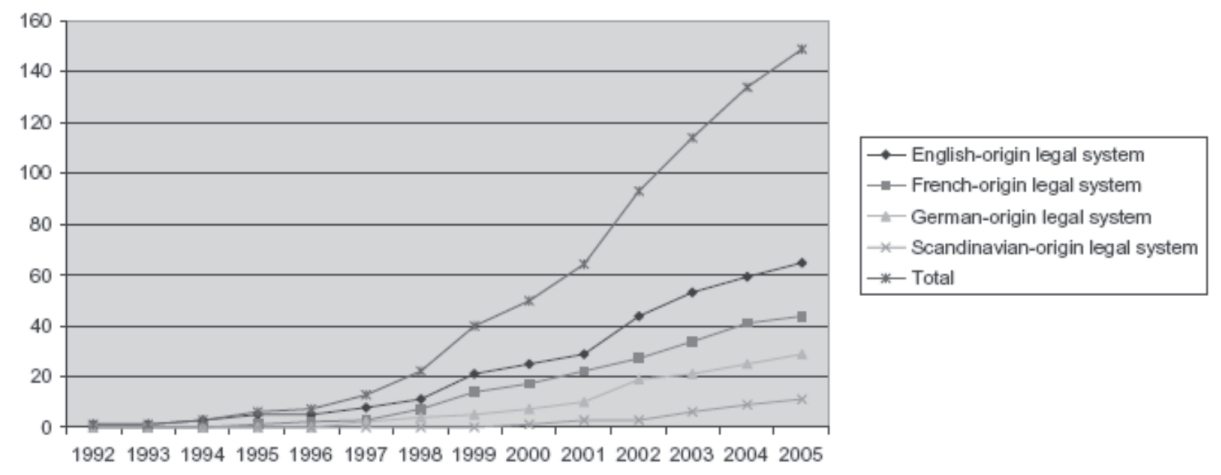

Figura 3. Difusão de Códigos de Governança Corporativa (Valor cumulativo). Fonte: Zattoni, A., \& Cuomo, F. (2008). Why adopt codes of good governance? A comparison of institutional and efficiency perspectives (p. 10). Corporate Governance, 16(1), 1-15.

A edição dos códigos de boas práticas de governança tem tido sua importância destacada principalmente nos últimos 10 anos (Zattoni \& Cuomo, 2008), mas teve início há muitos anos. Aguilera e Cuervo-Cazurra (2004) e Enrione et al. (2004) apontam que o primeiro código de governança corporativa foi editado nos Estados Unidos, no ano de 1978, pelo Business Roundtable (associação de executivos americanos), mais especificamente por J. Paul Austins, presidente executivo da Cola-Cola, naquela época. Intitulado como The Role and Composition of The Board of Directors of The Large Publicly Owned Corporation, o relatório foi resposta à onda de tomadas hostis de controle de algumas organizações (hostile takeovers), que ocorreram naqueles anos, assim como comportamentos considerados criminosos (Monks \& Minow, 2004).

Nos anos seguintes, tanto o Roundtable, quanto a Securities Exchange Commission (agência reguladora do mercado de capitais americano) e a New York Stock Exchange (bolsa de valores de Nova York) continuaram a reeditar códigos de boa governança. Somente uma década depois outro país veio a editar um código (Aguilera \& Cuervo-Cazurra, 2004). Em 1989 a bolsa de valores de Hong Kong (Hong Kong Stock Exchange) publicou seu primeiro código denominado Code of Best Practice, Listing Rules, e, em 1991, a Irish Association of Investment Managers editou o documento intitulado Statement of Best Practice on the Role and Responsibility of Directors of Publicly Listed Companies. Contudo, como apontam Aguilera e Cuervo-Cazurra (2004) e Enrione et al. (2006), foi na década de noventa que a edição de códigos de governança corporativa se disseminou, seguindo o Cadbury Committee Report: The Financial Aspects of Corporate Governance, publicado em 1992 no Reino Unido.

O relatório Cadbury marcou o fim da experimentação acerca dos códigos de 
governança e estabeleceu os fundamentos para uma efetiva regulação da governança corporativa (Enrione et al., 2006). De acordo com Aguilera e CuervoCazurra (2004), o código foi editado devido à ausência de confiabilidade dos relatórios financeiros das companhias abertas inglesas, assim como por causa das dificuldades que os auditores tinham de salvaguardar tais relatórios com as informações disponibilizadas pelas companhias. Segundo esses autores, o relatório Cadbury também enfatizou a necessidade de conselheiros independentes da gestão da companhia, do maior envolvimento dos acionistas na gestão, assim como de se estabelecer comitês especializados no conselho (p. ex. comitê de auditoria).

Do ponto de vista institucional, o relatório Cadbury estabeleceu-se como padrão de governança corporativa a ser seguido por editores de códigos dessa natureza (bolsas de valores, governos, associação de conselheiros e executivos, associações de profissionais contábeis e jurídicos e associações de investidores), apontando as linhas gerais para sua disseminação ao redor do mundo. Nas palavras de Enrione et al. (2006, p. 967, tradução nossa), "para se tornar uma ideia global, códigos de boa governança necessitavam ser um padrão amplamente compartilhado e endossado por uma rede de atores tidos como legítimos".

Diante das condições que garantem a legitimidade das práticas, vista aqui como um elemento estrutural, práticas de governança corporativa devem ter certo grau de densidade dentro dos sistemas sociais nos quais operam, que, no caso dessas práticas, envolvem a adoção nos mercados nacionais pelas empresas de capital aberto, mais até do que de sua disseminação ao redor do mundo. Em outras palavras, as práticas de governança corporativa devem ser institucionalizadas no mercado, vistas como um modelo socialmente desejado, portanto legítimo (Meyer \& Rowan, 1977; Tolbert \& Zucker, 1983). Assim, essa trajetória de difusão nos mercados nacionais envolve diferentes processos de institucionalização, já que pressupomos que os mercados estão imersos relacionalmente (Granovetter, 1985) e institucionalmente (Fligstein \& Choo, 2005; Fligstein \& Freeland, 1995).

Enquanto mercado nacional, o Brasil teve seu código de boas práticas de governança corporativa editado somente em 1999 pelo Instituto Brasileiro de Governança Corporativa [IBGC], associação sem fins lucrativos, que foi criada para disseminar tais práticas (IBGC, 2006). Mais tarde, o órgão de regulamentação do mercado de ações brasileiro, a Comissão de Valores Imobiliários, também editou sua cartilha de boas práticas de governança para empresas de capital aberto (CVM, 2002). Vale destacar que, no Brasil, diferentemente de outros países, o grande conflito de agência ocorre entre acionistas minoritários e majoritários que exercem o controle da organização, e não entre acionistas minoritários (principal) e administradores (agente) (Bertucci et al., 2006). Esses 
aspectos condicionam a forma pela qual as práticas de governança foram institucionalizadas no país (Fligstein \& Freeland, 1995), resultando em forma própria de governança, porém isomórfica com as demais.

Talvez seja por conta das peculiaridades do mercado nacional e, também, é claro, diante do contexto institucional nada propício ao desenvolvimento do mercado de ações (vide Gorga, 2004; La Porta et al., 1998) que os agentes do mercado brasileiro de ações resolveram criar um mercado paralelo ao tradicional: o Novo Mercado da Bovespa. Inspirado na experiência alemã de criação de um mercado de ações diferenciado (o Neuer Markt), em 11 de dezembro de 2000 a Bolsa de Valores de São Paulo criou uma listagem separada de organizações denominada Novo Mercado (Ribeiro \& Famá, 2002), tida como o grande alavancador da adoção de práticas de governança no Brasil (Bertucci et al., 2006; Carvalho, 2002).

Segundo Ribeiro e Famá (2002, p. 35), o "Novo Mercado da Bovespa é uma seção destinada à negociação de companhias que se submetam [voluntariamente] a exigências mais avançadas, em termos de direitos dos acionistas investidores e melhores práticas de governança corporativa”. Como aponta a Bovespa (2009),

a entrada de uma companhia no Novo Mercado ocorre por meio da assinatura de um contrato e implica a adesão a um conjunto de regras societárias, genericamente chamadas de "boas práticas de governança corporativa", mais exigentes do que as presentes na legislação brasileira. Essas regras, consolidadas no Regulamento de Listagem do Novo Mercado, ampliam os direitos dos acionistas, melhoram a qualidade das informações usualmente prestadas pelas companhias, bem como a dispersão acionária e, ao determinar a resolução dos conflitos societários por meio de uma Câmara de Arbitragem, oferecem aos investidores a segurança de uma alternativa mais ágil e especializada.

A principal inovação na prática de governança que as normas do Novo Mercado geram, em relação à legislação, é a exigência de que o capital social da companhia seja composto somente por ações ordinárias, isto é, ações com direito a voto. Além disso, as organizações devem: estender para todos os acionistas as mesmas condições obtidas pelos controladores por ocasião da venda do controle da companhia (tag along); realizar oferta pública de aquisição de todas as ações em circulação, no mínimo, pelo valor econômico, no caso de fechamento do capital; ter no mínimo 5 conselheiros, com mandato unificado, no qual $20 \%$ devem ser independentes; melhorar as informações prestadas ao mercado, além de aderir a padrões internacionais; manter pelo menos 25\% das ações em circulação; aderir à Câmara de Arbitragem do Mercado para resolução de conflitos societários; entre outras exigências (Bovespa, 2009).

Em paralelo, assumindo que as regras do Novo Mercado da Bovespa são muito 
restritivas em relação ao padrão institucionalizado no mercado (Carvalho, 2002), com não muitas organizações possíveis de satisfazer a suas exigências em curto prazo, a Bovespa criou os Níveis Diferenciados de Governança Corporativa, que discrimina as organizações listadas no mercado tradicional das demais empresas. Além do Novo Mercado, já apresentado, há mais dois níveis de governança corporativa: o Nível 1, que apresenta maior exigência de transparência; e o Nível 2, que é semelhante ao Novo Mercado, exceto pela aceitação de ações preferenciais na configuração do capital da organização (Bovespa, 2009).

A criação de mercados alternativos destaca-se como importante mecanismo para garantir que o conteúdo normativo das práticas de governança corporativa seja incorporado pelas organizações de capital aberto (Fiss, 2008). Como destaca Capron e Guillén (2009), os direitos e obrigações dos vários stakeholders são definidos e compelidos de acordo com as instituições de governança corporativa de um país. Entre as várias instituições vigentes (vide Roe, 2005), algumas apresentam caráter formal regulatório; p.ex. leis, marcos regulatórios e códigos. Porém, além do caráter coercitivo das obrigações formais, a adesão a mercados diferenciados pode ser vista como fator que apoia e habilita as ações das organizações de capital de aberto, já que ela garante maior grau de confiança do mercado, simplesmente por se submeterem ao conteúdo de uma regra aceita como legítima (Capron \& Guillén, 2009). Dessa forma, organizações que estão vinculadas a um elemento legitimado tendem a ser vistas também como legitimadas por esse elemento. No caso específico do mercado de ações brasileiro, a adesão a mercados diferenciados. Por exemplo, como aponta Carvalho (2002, pp. 2728, grifo do autor), “o Novo Mercado funciona como um selo de qualidade cujo valor reside nas obrigações contratuais assumidos pela empresa na maneira como a Bovespa administra tais contratos".

Esses aspectos demonstram o caráter generalizador que a legitimidade tem enquanto critério de avaliação social: os mercados, enquanto audiência das organizações, generalizam o comportamento das empresas que pertencem a determinada categoria social (p.ex. organizações com boas práticas de governança) das demais (p.ex. organizações que não aderem a práticas de governança), não considerando as empresas isoladamente, mas a categoria à qual pertencem. Para ilustrar tal forma de avaliação do mercado, pode-se destacar os argumentos de Borgerth (2007, p. 6), quando essa cita a avaliação do mercado sobre o escândalo que envolve a Enron e sua empresa de auditoria naquele momento, a Arthur Andersen:

O mercado, nesse sentido, costuma ser bastante cruel, generalizando comportamentos isolados como se eles ilustrassem a postura de todos e, assim, desestimulando justamente aqueles que se esforçam para se manter dentro 
dos padrões éticos de sua profissão, que acabam sendo estigmatizados como os outros poucos que fogem da regra.

Em suma, por causa desse caráter generalizador atribuído pelas audiências às organizações que adotam práticas de governança corporativa, além, é claro, dos aspectos teóricos expostos, que propusemos que ela pode ser vista enquanto dimensão institucional.

\section{Considerações Finais}

Com este ensaio teórico, buscamos delinear uma visão institucional acerca da governança corporativa, destacando suas dimensões e suas instituições, bem como o processo de institucionalização de tais práticas. O ponto central dos nossos argumentos em favor de apoiar uma perspectiva de análise institucional é que a adoção de práticas de governança corporativa, além de provavelmente aumentar a eficiência dos sistemas de governança (La Porta et al., 1998), também confere legitimidade às organizações (Davis, 2005). Vale destacar que o fato de nos apoiarmos no uso de tal perspectiva não nega outras já correntemente empregadas no estudo do fenômeno, como a teoria da agência e a teoria dos custos de transação. Pelo contrário, buscamos complementá-las, ressaltando os aspectos sociais, simbólicos, institucionais que envolvem a adoção dessas práticas.

A partir de tal visão, apontamos que como locus do desenvolvimento das práticas de governança corporativa temos as organizações de capital aberto, mais especificamente, sua alta cúpula diretiva, que, em conjunto com as outras organizações envolvidas com o mercado acionário, são concebidas como esfera social própria, consolidando-se como campo organizacional, em que imperam aspectos institucionais e culturais acerca da atividade financeira dessas organizações.

Nessa linha de raciocínio, as empresas de capital aberto com negociação em bolsa se configuraram como campo relevante para se estudar o fenômeno da legitimidade, porque ele envolve, mais que decisões técnicas, expectativas dos investidores sobre as organizações listadas. Assim, aspectos sociais relacionados com a legitimidade das organizações afloram como importantes condicionantes da capacidade das organizações em angariar recursos, já que elas são dependentes de sua avaliação no mercado para consegui-los.

Em decorrência de tais apontamentos, podemos desdobrar algumas sugestões de investigação. A primeira delas remete à necessidade de investigar o processo de institucionalização das práticas de governança corporativa no Brasil, já que no país 
foram incorporadas práticas que surgiram em países em que o problema de agência ocorre por causa do conflito entre interesses de acionistas minoritários e executivos das organizações, o que difere do caso brasileiro, onde a propriedade é extremamente centralizada. Em segundo lugar, estudos futuros poderiam verificar como o ambiente institucional cultural brasileiro condicionou a institucionalização das práticas de governança no Brasil, considerando que, enquanto regra estruturante, seus princípios já foram definidos internacionalmente. Em terceiro lugar, fundamental para se entender o efeito da legitimidade no mercado acionário brasileiro, é essencial compreender quais são os elementos relacionados às práticas de governança que têm efeito legitimador das organizações. Por fim, é necessário destacar que existe uma dinâmica social no mercado acionário brasileiro que envolve diversos agentes, entre eles os fundos de pensão, as associações de bancos, acionistas, sociedade civil, IBGC, CVM, Bovespa, entre outros, cuja investigação do papel de tais agentes no processo de institucionalização das práticas de governança pode apontar resultados interessantes.

\section{Artigo recebido em 13.07.2010. Aprovado em 27.08.2010.}

\section{NotAs}

${ }^{1}$ Este artigo foi selecionado entre os $10 \%$ melhores trabalhos apresentados no Encontro de Estudos Organizacionais de 2010, sendo indicado para avaliação em periódicos pelo regime de fast track.

${ }^{2}$ Este texto é resultado parcial da tese de doutorado de Luciano Rossoni, intitulada Governança Corporativa, Legitimidade e Desempenho das Organizações Listadas na Bovespa, orientada pelo professor Clóvis L. Machado-da-Silva no Programa de Pós-Graduação em Administração da Universidade Federal do Paraná.

\section{ReferênCIAS Bibliográficas}

Abrahamson, E., \&

Fairchild, G. (1999).

Management Fashion: lifecycles, triggers, and collective learning processes. Administrative Science Quarterly, 44(4), 708-740.

Aguilera, R. V., \&

Cuervo-Cazurra, A. (2004).

Codes of good governance worldwide: what is the trigger? Organization Studies, 25(3), 415-443.
Aguilera, R. V., \&

Jackson, G. (2003).

The cross-national diversity of corporate governance: dimensions and determinants. Academy of Management Review, 28(3), 447-465.

Albuquerque, J. B., Filho, \& Machado-da-Silva, C. L. (2009).

Práticas organizacionais e estrutura de relações no campo do desenvolvimento metropolitano. Revista de Administração Contemporânea, 13(4), 626-646. 
Berle, A. A., \&

Means, G. C. (1932/1991).

The modern corporation and private property. New Brunswick: Transaction Publishing.

Bertucci, J. L. A.,

Bernardes, P., \&

Brandão, M. M. (2006).

Políticas e práticas de governança corporativa em empresas brasileiras de capital aberto. Revista de Administração da USP, 4I(2), 183196.

Blair, M. M. (1995).

Ownership and control: re-thinking corporate governance for the twenty-first century. Washington: Brookings Inst.

Bolsa de Valores de São Paulo. (2009).

Governança corporativa comparativo entre segmentos. São Paulo: Autor. Recuperado em 5 outubro, 2009, de http:// www.bmfbovespa.com.br/Empresas/ InstInfoEmpresas/SegmentoList

Borgerth, V. M. C. (2007).

SOX: Entendendo a Lei SarbanesOxley: um caminho para a informação transparente. São Paulo: Thomson.

Capron, L., \&

Guillén, M. (2009).

National corporate governance and post acquisition target reorganization. Strategic Management Journal, 30(8), 803-833.

Carvalho, A. G. (2002).

Governança corporativa no Brasil em perspectiva. Revista de Administração da USP, 37(3), 19-32.
Chowdhury, S. D., \&

Wang, E. Z. (2009).

Institutional activism types and CEO compensation: a time-series analysis of large Canadian corporations. Journal of Management, 35(1), 5-36.

Comissão de Valores Mobiliários. (2002). Recomendações da CVM sobre governança corporativa. Rio de Janeiro: Autor.

Davis, G. F. (2005).

New directions in corporate governance. Annual Review of Sociology, 31, 143-162.

Enrione, A.,

Mazza, C., \&

Zerboni, F. (2006).

Institutionalizing codes of governance. American Behavioral Scientist, 49(7), 961-973.

Fama, E. F. (1970).

Efficient capital markets: a review of theory and empirical work. Journal of Finance, 25(2), 383-417.

Fiss, P. C. (2008).

Institutions and corporate governance. In R. Greenwood, C. Oliver, K. Sahlin-Andersson, \& R. Suddaby (Eds.), The sage handbook of organizational institutionalism (pp. 389-410). London: Sage.

Fligstein, N., \&

Choo, J. (2005).

Law and corporate governance. Annual Review of Law and Social Science, 1, 61-84. 
Fligstein, N., \&

Freeland, R. (1995).

Theoretical and comparative perspectives on corporate organization. Annual Review of Sociology, 21, 21-43.

Gorga, E. (2004).

A cultura brasileira como fator determinante na governança corporativa e no desenvolvimento do mercado de capitais. Revista de Administração da USP, 39(4), 309-326.

Granovetter, M. S. (1985).

Economic action and social structure: the problem of embeddedness. American Journal of Sociology, 91(3), 481-510.

Greenwood, R.,

Suddaby, R., \&

Hinings, C. R. (2002).

Theorizing change: the role of professional associations in the transformation of institutionalized fields. Academy of Management Journal, 45(1), 58-80.

Grün, R. (2003).

Atores e ações na construção da governança corporativa brasileira. Revista Brasileira de Ciências Sociais, 18(52), 139-161.

Instituto Brasileiro de Governança Corporativa. (2006).

Uma década de governança corporativa: história do IBGC, marcos e lições da experiência. São Paulo: Saint Paul Institute of Finance/ Saraiva.
Instituto Brasileiro de Governança Corporativa. (2009).

Código de melhores práticas de governança corporativa (4a ed.). São Paulo: Autor.

Jensen, M. C., \&

Meckling, W. (1976).

Theory of the firm: managerial behavior, agency costs and ownership structure. Journal of Financial Economics, 3(4), 305-360.

Jones, T. M., \&

Goldberg, L. D. (1982).

Governing the large corporation: more arguments for public directors. Academy of Management Review, 7(4), 603-611.

La Porta, R.,

Lopez-de-Silanes, F.,

Shleifer, A., \&

Vishny, R. (1998).

Law and finance. Journal of Political Economy, 106(5), 1113-1155.

Meyer, J. W., \&

Rowan, B. (1977).

Institutionalized organizations: formal structure as myth and ceremony. American Journal of Sociology, 83(2), 340-363.

Monks, R., \&

Minow, N. (2004).

Corporate governance. Cambridge: Basil Blackwell.

Nee, V., \&

Swedberg, R. (2005).

Economic sociology and new institutional economics. In C. Ménard \& M. M. Shirley (Eds.), Handbook of new institutional economics (pp. 789-818). Netherlands: Springer. 
North, D. C. (1990). Institutions, institutional change, and economic performance. Cambridge: Cambridge University Press.

Organization for Economic Cooperation and Devolopment. (2004).

OECD principles of corporate governance. Paris: Author.

Pound, J. (1995).

The promise of the governed corporation. Harvard Business Review, 73(2), 89-98.

Ribeiro, R. M., Neto, \&

Famá, R. (2002).

Uma alternativa de crescimento para o mercado de capitais brasileiro - o novo mercado. Revista de Administração da USP, 37(1), 29-38.

Roe, M. J. (2005).

The institutions of corporate governance. In C. Ménard \& M. M. Shirley (Eds.), Handbook of new institutional economics (pp. 371399). Netherlands: Springer.

Scott, W. R. (2008).

Institutions and organizations: ideas and interests (3th ed.). Thousand Oaks: Sage.

Scott, W. R. (1994).

Institutions and organizations: toward a theoretical synthesis. In W. R. Scott \& J. W. Meyer and Associates, Institutional environments and organizations: structural complexity and individualism (pp. 55-80). Thousand Oaks: Sage.
Shleifer, A., \&

Vishny, R. (1997).

A survey of corporate governance. Journal of Finance, 52(2), 737-783.

Stanfield, J. R., \&

Carrol, M. C. (2004).

Governance and the legitimacy of corporate power: a path for convergence of heterodox economic? Journal of Economic Issues, 38(2), 363-370.

Strang, D., \&

Macy, M. M. (2001).

In search of excellence: fads, success stories, and adaptive emulation. American Journal of Sociology, 107(1), 147-182.

Tolbert, P. S., \&

Zucker, L. (1983).

Institutional sources of change in the formal structure of organizations: the diffusion of civil service reform, 18801935. Administrative Science Quarterly, 28(1), 22-39.

Williams, E. E., \&

Findlay, M. C. (1984).

Corporate governance: a problem of hierarchies and self interest. American Journal of Economics and Sociology, 43(1), 19-36.

Williamson, O. E. (1996).

The mechanisms of governance. New York: Oxford University Press.

Zattoni, A., \&

Cuomo, F. (2008).

Why adopt codes of good governance? A comparison of institutional and efficiency perspectives. Corporate Governance, 16(1), 1-15. 